Rotational study of the $\mathrm{NH}_{3}-\mathrm{CO}$ complex: Millimeter-wave measurements and ab initio calculations

L. A. Surin', A. Potapov, A. A. Dolgov, I. V. Tarabukin, V. A. Panfilov, S. Schlemmer, Y. N. Kalugina, A. Faure, and A. van der Avoird'

Citation: The Journal of Chemical Physics 142, 114308 (2015); doi: 10.1063/1.4915119

View online: http://dx.doi.org/10.1063/1.4915119

View Table of Contents: http://aip.scitation.org/toc/jcp/142/11

Published by the American Institute of Physics

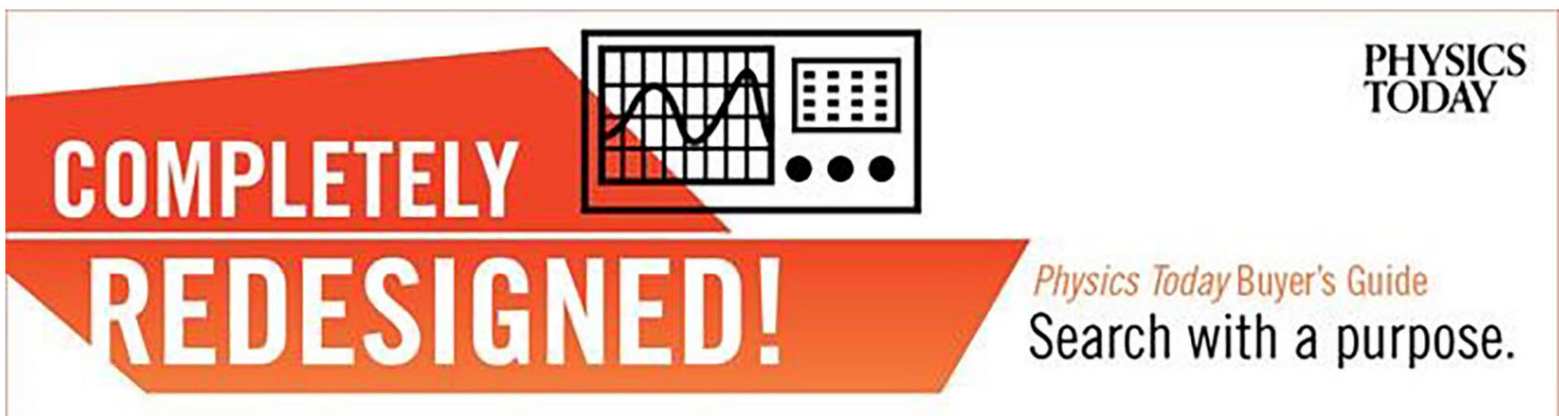




\title{
Rotational study of the $\mathrm{NH}_{3}-\mathrm{CO}$ complex: Millimeter-wave measurements and $a b$ initio calculations
}

\author{
L. A. Surin, ${ }^{1,2, a)}$ A. Potapov, ${ }^{1}$ A. A. Dolgov,${ }^{2}$ I. V. Tarabukin, ${ }^{2}$ V. A. Panfilov, ${ }^{2}$ S. Schlemmer, \\ Y. N. Kalugina, ${ }^{3}$ A. Faure, ${ }^{4,5}$ and A. van der Avoird ${ }^{6, b)}$ \\ ${ }^{1}$ I. Physikalisches Institut, University of Cologne, Zülpicher Str. 77, 50937 Cologne, Germany \\ ${ }^{2}$ Institute of Spectroscopy, Russian Academy of Sciences, Fizicheskaya Str. 5, 142190 Troitsk, Moscow, Russia \\ ${ }^{3}$ Department of Optics and Spectroscopy, Tomsk State University, 36 Lenin av., 634050 Tomsk, Russia \\ ${ }^{4}$ Université de Grenoble Alpes, IPAG, F-38000 Grenoble, France \\ ${ }^{5}$ CNRS, IPAG, F-38000 Grenoble, France \\ ${ }^{6}$ Theoretical Chemistry, Institute for Molecules and Materials, Radboud University Nijmegen, \\ Heyendaalseweg 135, 6525 AJ Nijmegen, The Netherlands
}

(Received 30 January 2015; accepted 5 March 2015; published online 19 March 2015)

\begin{abstract}
The rotational spectrum of the van der Waals complex $\mathrm{NH}_{3}-\mathrm{CO}$ has been measured with the intracavity OROTRON jet spectrometer in the frequency range of 112-139 GHz. Newly observed and assigned transitions belong to the $K=0-0, K=1-1, K=1-0$, and $K=2-1$ subbands correlating with the rotationless $\left(j_{k}\right)_{\mathrm{NH} 3}=0_{0}$ ground state of free ortho- $\mathrm{NH}_{3}$ and the $K=0-1$ and $K=2-1$ subbands correlating with the $\left(j_{k}\right)_{\mathrm{NH} 3}=1_{1}$ ground state of free para- $\mathrm{NH}_{3}$. The (approximate) quantum number $K$ is the projection of the total angular momentum $J$ on the intermolecular axis. Some of these transitions are continuations to higher $J$ values of transition series observed previously [C. Xia et al., Mol. Phys. 99, 643 (2001)], the other transitions constitute newly detected subbands. The new data were analyzed together with the known millimeter-wave and microwave transitions in order to determine the molecular parameters of the ortho- $\mathrm{NH}_{3}-\mathrm{CO}$ and para- $\mathrm{NH}_{3}-\mathrm{CO}$ complexes. Accompanying ab initio calculations of the intermolecular potential energy surface (PES) of $\mathrm{NH}_{3}-\mathrm{CO}$ has been carried out at the explicitly correlated coupled cluster level of theory with single, double, and perturbative triple excitations and an augmented correlation-consistent triple zeta basis set. The global minimum of the five-dimensional PES corresponds to an approximately T-shaped structure with the $\mathrm{N}$ atom closest to the $\mathrm{CO}$ subunit and binding energy $D_{e}=359.21 \mathrm{~cm}^{-1}$. The bound rovibrational levels of the $\mathrm{NH}_{3}-\mathrm{CO}$ complex were calculated for total angular momentum $J=0-6$ on this intermolecular potential surface and compared with the experimental results. The calculated dissociation energies $D_{0}$ are 210.43 and $218.66 \mathrm{~cm}^{-1}$ for ortho- $\mathrm{NH}_{3}-\mathrm{CO}$ and para- $\mathrm{NH}_{3}-\mathrm{CO}$, respectively. (C) 2015 AIP Publishing LLC. [http://dx.doi.org/10.1063/1.4915119]
\end{abstract}

\section{INTRODUCTION}

One of the reasons to investigate the $\mathrm{NH}_{3}-\mathrm{CO}$ van der Waals complex concerns interpretation of the spectroscopic data coming from planetary atmospheres and the interstellar gas, because both ammonia and carbon monoxide are trace constituents in the solar system and they are present on ices in molecular clouds. ${ }^{1,2}$ Another motivation to study the $\mathrm{NH}_{3}-\mathrm{CO}$ system is its relevance to interactions between carbonyl and amine groups, which are important in many biological systems and required for modeling of the structures and dynamics of proteins. High resolution spectroscopy of van der Waals complexes together with ab initio calculations of the intermolecular potential is an efficient tool for reliable elucidation of the intermolecular forces, because bound states of the complexes are sensitive to the interaction potential.

The first spectroscopic observations of $\mathrm{NH}_{3}-\mathrm{CO}$ have been carried out by Fraser et al., ${ }^{3}$ who observed the complex in the $6-21 \mathrm{GHz}$ region using the technique of molecular beam

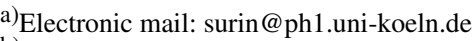

b)Electronic mail: A.vanderAvoird@ @heochem.ru.nl
}

electric resonance (MBER). They assigned a series of pure rotational transitions of the $\mathrm{NH}_{3}-\mathrm{CO}$ complex (and less complete series of its $\mathrm{ND}_{3}, \mathrm{ND}_{2} \mathrm{H}, \mathrm{NDH}_{2},{ }^{13} \mathrm{CO}$ isotopologues) in the $K=0$ ground state. The ${ }^{14} \mathrm{~N}$ quadrupole hyperfine structure of the observed transitions was resolved and analyzed, which provides the information that $\mathrm{NH}_{3}-\mathrm{CO}$ is not hydrogen bonded and the $\mathrm{N}$ atom is closest to the $\mathrm{CO}$ subunit. Two further nearly degenerate pairs of series in the $K=0$ and $K=1$ excited states were detected. However, the exact nature of these excited states was not clear, and only limited information could be determined regarding the energy level pattern of $\mathrm{NH}_{3}-\mathrm{CO}$.

Subsequently, a more extensive study of $\mathrm{NH}_{3}-\mathrm{CO}$ has been done by McKellar and co-workers, ${ }^{4}$ where rovibrational (C-O stretching $\approx 2143 \mathrm{~cm}^{-1}$ ) and pure rotational $(76-106 \mathrm{GHz})$ transitions were measured in a pulsed jet supersonic expansion. The spectra included several subbands of infrared (IR) $v_{\mathrm{CO}}=1-0$ transitions, $K=1-0, K=0-1$, and $K=2-1$, and a number of subbands of pure rotational millimeter-wave (MMW) transitions, $K=0-0, K=1-1, K=1-0, K=2-1$, in the $v_{\mathrm{CO}}=0$ ground state. In that work, the authors utilized the free internal rotation model to label the internal rotor states of $\mathrm{NH}_{3}-\mathrm{CO}$, where $j_{\mathrm{NH} 3}$ and $j_{\mathrm{CO}}$ are quantum numbers for the in- 
ternal rotations of the $\mathrm{NH}_{3}$ and $\mathrm{CO}$ subunits. The total angular momentum $J$ and its projection $K$ on the intermolecular axis are the other useful quantum numbers.

As in the case of many other weakly bound complexes, for example, $\mathrm{H}_{2}-\mathrm{CO},{ }^{5,6} \mathrm{~N}_{2}-\mathrm{CO},{ }^{7,8} \mathrm{CH}_{4}-\mathrm{CO},{ }^{9-11}$ the symmetry and nuclear spin modifications of the parent $\mathrm{NH}_{3}$ molecule remain important in the $\mathrm{NH}_{3}-\mathrm{CO}$ complex. Ammonia is a pyramidal symmetric top molecule with $C_{3 V}$ symmetry. Tunneling of the $\mathrm{N}$ atom through the plane of the $\mathrm{H}$ atoms causes an inversion splitting of the energy levels, with a magnitude of about $24 \mathrm{GHz}$ in the ground vibrational state of free $\mathrm{NH}_{3}$. Due to symmetry and nuclear spin statistics of the three equivalent protons in $\mathrm{NH}_{3}$ all levels are separated into two distinct groups corresponding to complexes formed from ortho- or para- $\mathrm{NH}_{3} .{ }^{12}$ In spite of the higher multiplicity of the ortho nuclear spin states, the larger number of the para rotational levels results in approximately equal populations of the orthoand para- $\mathrm{NH}_{3}$ species. More details on the symmetry are given in Sec. IV. In the case of the $\mathrm{NH}_{3}-\mathrm{CO}$ complex formed in a cold jet expansion, we need to consider only the lowest rotational energy level of each nuclear spin species of ammonia, namely, $\left(j_{k}\right)_{\mathrm{NH} 3}=0_{0}$ for ortho $-\mathrm{NH}_{3}$ and $1_{1}$ for para- $\mathrm{NH}_{3}$, where $k$ is the projection of the $\mathrm{NH}_{3}$ angular momentum $j$ on the threefold symmetry axis.

Up to now, we have not been aware of any potential energy surface (PES) calculations for the $\mathrm{NH}_{3}-\mathrm{CO}$ system. This paper presents the first ab initio PES of $\mathrm{NH}_{3}-\mathrm{CO}$ carried out at the explicitly correlated coupled cluster level of theory with single, double, and perturbative triple excitations [CCSD(T)-F12a] and an augmented correlation-consistent triple zeta (aVTZ) basis set. The bound rotational levels of the $\mathrm{NH}_{3}-\mathrm{CO}$ complex were calculated for total angular momentum $J=0-6$ on this intermolecular potential surface and compared with the experimental results for both the ortho- and para- $\mathrm{NH}_{3}-\mathrm{CO}$ spin modifications. Our new measurements of $\mathrm{NH}_{3}-\mathrm{CO}$ extend the microwave $(\mathrm{MW})^{3}$ and $\mathrm{MMW}^{4}$ transition series observed previously at lower frequencies to higher $J$ values and reveal other newly detected subbands.

\section{EXPERIMENTAL MEASUREMENTS AND EMPIRICAL ANALYSIS}

\section{A. Millimeter-wave experiment}

MMW measurements in the frequency range of 112-139 $\mathrm{GHz}$ were made using the intracavity OROTRON jet spectrometer. The OROTRON spectrometer ${ }^{13}$ combined with molecular jet expansion is a well-known technique ${ }^{14}$ that has been used for more than ten years for the measurements of spectra of weakly bound complexes.

Briefly, the MMW generator OROTRON is placed in a vacuum chamber together with a supersonic jet. The free jet is injected into the OROTRON cavity perpendicularly to its axis. A high $Q$-factor $\left(\approx 10^{4}\right)$ of the cavity results in 100 effective passes of the radiation through the jet. Absorption in the cavity causes changes of the electron current in the collector circuit of the OROTRON and is detected very sensitively by measuring these current changes. A small part of the MMW radiation is taken out from the cavity through coupling openings in a spher- ical mirror and mixed on a Schottky diode with the radiation of a MW synthesizer for frequency determination. The range of operation of the present OROTRON tube is $112-155 \mathrm{GHz}$ with a few small gaps. A detailed description of the spectrometer has been published elsewhere. ${ }^{14}$

For the production of complexes, we used a gas mixture of $10 \%$ of $\mathrm{NH}_{3}$ in $\mathrm{CO}$ at a backing pressure of 3-4 bars. The gas mixture was adiabatically expanded into the OROTRON cavity through a pulsed pin nozzle (General Valve, Series 9) with an opening diameter of $1 \mathrm{~mm}$ operated at a repetition rate of $8-12 \mathrm{~Hz}$.

In addition to the $\mathrm{NH}_{3}-\mathrm{CO}$ lines, many transitions of the $\mathrm{CO}$ dimer were also observed in the spectrum but most of them could be easily distinguished from the $\mathrm{NH}_{3}-\mathrm{CO}$ lines due to the previous millimeter-wave survey of $(\mathrm{CO})_{2} \cdot{ }^{15}$

\section{B. Observed rotational spectrum}

The previous IR and MMW studies ${ }^{4}$ have shown that the spectrum and energy level pattern of ortho- $\mathrm{NH}_{3}-\mathrm{CO}$ are relatively simple, closely resembling those of the rare gas-CO complexes. The situation for para- $\mathrm{NH}_{3}-\mathrm{CO}$ was more complicated, and the observed states had $K$ values differing by \pm 1 from those of the analogous ortho- $\mathrm{NH}_{3}-\mathrm{CO}$ states. All observed para- $\mathrm{NH}_{3}-\mathrm{CO}$ rotational lines revealed a small (a few $\mathrm{MHz}$ ) doubling, not resolved in the IR spectrum.

The rotational energy levels of $\mathrm{NH}_{3}-\mathrm{CO}$ with $K=0,1$, and 2 up to $25 \mathrm{~cm}^{-1}$ are shown in Fig. 1 for ortho- $\mathrm{NH}_{3}$ (left diagram) and para- $\mathrm{NH}_{3}$ (right diagram). Spectroscopic parity labels $e(\varepsilon=+1)$ and $f(\varepsilon=-1)$ are used to assign the parity $p$ of individual levels according to the relation $p=\varepsilon(-1)^{J}$. The zero of energy for ortho- $\mathrm{NH}_{3}-\mathrm{CO}$ is simply fixed at the lowest $J=0$ level of the $K=0$ ground state of the complex; the zero of energy for para- $\mathrm{NH}_{3}-\mathrm{CO}$ is fixed at the $J=0$ (virtual) level of the $K=1$ ground state. The relative position of the ortho and para- $\mathrm{NH}_{3}-\mathrm{CO}$ energy scales is determined by the zeropoint levels of the ortho and para complexes obtained from the bound state calculations, see Sec. IV.

Using the reported data ${ }^{4}$ for ortho- $\mathrm{NH}_{3}-\mathrm{CO}$, we predicted and found 14 new transitions with higher $J$ values than accessed in the previous study. These include five $R(7)-R(11)$ transitions of the $K=1-0$ subband, four $R(16)-R(19)$ transitions of the $K=0-0$ subband, and five $R(16)-R(18)$ transitions of the $K=1-1$ subband. Also, we were able to detect for the first time the $K=2-1$ subband, which includes five $P_{e}(8)-P_{e}(12)$ and five $P_{f}(6)-P_{f}(10)$ transitions. A similar $K=2$ state was observed in the IR spectrum of ortho- $\mathrm{NH}_{3}-\mathrm{CO}$ for the excited $v_{\mathrm{CO}}=1$ state but not for the ground $v_{\mathrm{CO}}=0$ state. $^{4}$ Fig. 1 (left) shows the new $K=1-0$ and $K=2-1$ transitions with bold arrows and all previously observed transitions with thin arrows. The new $K=0-0$ and $K=1-1$ transitions connect levels located above $25 \mathrm{~cm}^{-1}$ and are not depicted on the diagram. The frequencies of all observed and assigned rotational lines for ortho- $\mathrm{NH}_{3}-\mathrm{CO}$ are listed in Table I.

For para- $\mathrm{NH}_{3}-\mathrm{CO}$, we have detected at first four $R(5)$ $R(8)$ transitions of the $K=2-1$ subband. They continue the transition series observed previously at lower frequencies ${ }^{4}$ to higher $J$ values. All observed $K=2-1$ transitions exhibit a splitting of about $1 \mathrm{MHz}$ in agreement with the trend from 


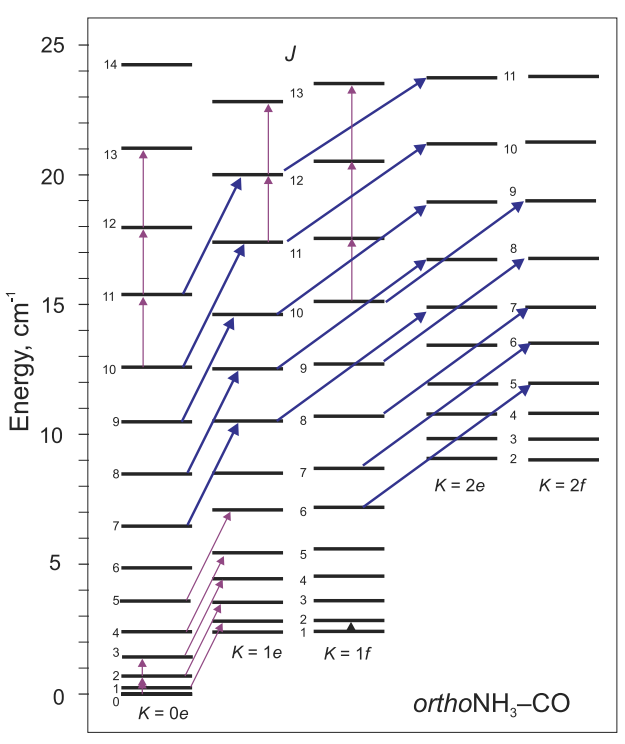

lower- $J$ lines. Then carefully searching we were able to detect the new $K=0-1$ subband and measured five $R(7)-R(11)$ transitions. This subband was not observed in the previous MMW study, although the rotational constants for the $K=0$ state were estimated from the IR spectrum. ${ }^{4}$ The new $K=0-1$ lines exhibit a doubling with quite large $65-75 \mathrm{MHz}$ splitting. At the beginning, we even overlooked these doublings and detected only one $K=0(e)-1(e)$ subband. But then, analysing the results of the bound state calculations (Sec. IV) that predict the $e / f$ splittings very accurately, the second $K=0(f)-1(f)$ subband was found. All new and previously observed ${ }^{3,4}$ rotational transitions are shown in Fig. 1 (right), and their frequencies and splittings are listed in Table II. The given frequencies from Refs. 3 and 4 represent the averaged values of two observed peaks (if they were resolved) for each transition.

The accuracy of frequency determination in the new measurements of both ortho- $\mathrm{NH}_{3}-\mathrm{CO}$ and para- $\mathrm{NH}_{3}-\mathrm{CO}$ is expected to be about $50 \mathrm{kHz}$. An exception is the position of the $K=0-0 R(19)$ transition of ortho- $\mathrm{NH}_{3}-\mathrm{CO}$ which could only be determined with a somewhat larger uncertainty of about $100 \mathrm{kHz}$. Fig. 2 shows an example of a recorded line, namely, the $R(6) K=2-1$ transition of para- $\mathrm{NH}_{3}-\mathrm{CO}$, demonstrating an $e / f$ symmetry splitting of $0.86 \mathrm{MHz}$.

\section{Empirical analysis}

The transitions of $\mathrm{NH}_{3}-\mathrm{CO}$ assigned in this work were fitted together with already known $\mathrm{MW}^{3}$ and MMW data. ${ }^{4}$ In the fitting procedure, the frequencies of the MMW and MW transitions were given weights of 1:50 according to the corresponding measurement accuracies. For ortho- $\mathrm{NH}_{3}-\mathrm{CO}$, we used an empirical energy expression in which each $K$-stack of levels was represented by a band origin $\sigma$ plus a power series in $\left[J(J+1)-K^{2}\right]$, and an additional power series in $J(J+1)$ describing the asymmetry splitting

$$
\begin{aligned}
E_{\text {total }}= & \sigma+B\left[J(J+1)-K^{2}\right]-D\left[J(J+1)-K^{2}\right]^{2} \\
& +H\left[J(J+1)-K^{2}\right]^{3} \\
& +L\left[J(J+1)-K^{2}\right]^{4}+\Delta E_{K},
\end{aligned}
$$

FIG. 1. Rotational energy levels and observed transitions of $\mathrm{NH}_{3}-\mathrm{CO}$. The relative position of the ortho and para$\mathrm{NH}_{3}-\mathrm{CO}$ energy scales is determined by the zero-point levels of the ortho and para complexes obtained from the bound state calculations, see Sec. IV. The new $\Delta K= \pm 1$ transitions are shown in bold (blue).

$$
\begin{aligned}
\Delta E_{K}= & \pm 1 / 2\left[b J(J+1)+d(J(J+1))^{2}\right. \\
& \left.+h(J(J+1))^{3}\right]
\end{aligned}
$$

In this expression, $B$ is equivalent to $[(B+C) / 2]$ and $b$ is equivalent to $[(B-C) / 2]$, where $B$ and $C$ are the nearly equal rotational constants of the complex, considered as a conventional near-prolate asymmetric rotor molecule. The asymmetry doubling term $\Delta E_{K}$ is equal to zero for $K=0$, and starts at $b$ for $K=1$, at $d$ for $K=2$, etc.

The results of the fit for ortho- $\mathrm{NH}_{3}-\mathrm{CO}$ are given in Table III together with the constants determined in the previous study. ${ }^{4}$ The value of the root mean squared deviation $\sigma_{\text {fit }}$ $=50 \mathrm{kHz}$ for the MMW transitions is close to our experimental uncertainty. The parameters for the $K=0$ and $K=1$ states agree well with those obtained in Ref. 4, but in the present analysis, two more centrifugal distortion constants $L$ and $h$ for the $K=1$ state had to be used because of the inclusion of higher- $J$ transitions in the fit. The accurate molecular parameters for the $K=2$ state were determined for the first time.

The asymmetry doubling term (2) was used only for the $K=1$ and $K=2$ states of ortho- $\mathrm{NH}_{3}-\mathrm{CO}$, but not for para$\mathrm{NH}_{3}-\mathrm{CO}$, which was analysed as a symmetric top molecule (expression (1) with $\Delta E_{K}=0$ ) following previous work. ${ }^{4}$ It was also shown ${ }^{4}$ that for the close-lying para- $\mathrm{NH}_{3}-\mathrm{CO}$ states with $K=0$ and 2, a Coriolis-type interaction should be introduced, linking levels of the same $J$ value with a term given by

$$
W=\beta\{[J(J+1)][J(J+1)-2]\}^{1 / 2} .
$$

Here, $\beta$ is a Coriolis-type interaction parameter representing a second order interaction. For all para- $\mathrm{NH}_{3}-\mathrm{CO}$ transitions exhibiting some degree of doubling, the mean center frequencies were used in the fit analysis.

The spectroscopic constants obtained for the observed states of para- $\mathrm{NH}_{3}-\mathrm{CO}$ are given in Table IV together with the constants determined in the previous study. ${ }^{4}$ Overall there is a good agreement between the parameters, but their values for the $K=0$ and $K=2$ states are determined now with significantly better accuracy. The root mean squared deviation $\sigma_{\text {fit }}=150 \mathrm{kHz}$ for the MMW transitions is larger than 
TABLE I. Measured $R$-branch transitions for the ortho- $\mathrm{NH}_{3}-\mathrm{CO}$ complex containing $\mathrm{NH}_{3}$ in the $\left(j_{k}\right)_{\mathrm{NH} 3}=0_{0}$ state. New values are given in bold.

\begin{tabular}{|c|c|c|}
\hline Assignment & & Frequency, $\mathrm{MHz}$ \\
\hline \multirow[t]{10}{*}{$K=1-0 ; j_{\mathrm{CO}}=1-0$} & $R(1)$ & $77357.037^{\mathrm{a}}$ \\
\hline & $R(2)$ & $83995.766^{\mathrm{a}}$ \\
\hline & $R(3)$ & $90521.435^{\mathrm{a}}$ \\
\hline & $R(4)$ & $96933.759^{\mathrm{a}}$ \\
\hline & $R(5)$ & $103233.241^{\mathrm{a}}$ \\
\hline & $R(7)$ & 115498.157 \\
\hline & $R(8)$ & 121467.514 \\
\hline & $R(9)$ & 127331.395 \\
\hline & $R(10)$ & 133092.993 \\
\hline & $R(11)$ & 138755.753 \\
\hline \multirow[t]{10}{*}{$K=0-0 ; j_{\mathrm{CO}}=0-0$} & $R(0)$ & $6971.073^{\mathrm{b}}$ \\
\hline & $R(1)$ & $13939.502^{\mathrm{b}}$ \\
\hline & $R(2)$ & $20902.645^{b}$ \\
\hline & $R(10)$ & $76097.934^{\mathrm{a}}$ \\
\hline & $R(11)$ & $82893.361^{\mathrm{a}}$ \\
\hline & $R(12)$ & $89656.786^{\mathrm{a}}$ \\
\hline & $R(16)$ & 116333.267 \\
\hline & $R(17)$ & 122893.771 \\
\hline & $R(18)$ & 129404.586 \\
\hline & $R(19)$ & 135863.150 \\
\hline \multirow[t]{5}{*}{$K=1(e)-1(e) ; j_{\mathrm{CO}}=1-1$} & $R(11)$ & $81760.844^{\mathrm{a}}$ \\
\hline & $R(12)$ & $88461.611^{\mathrm{a}}$ \\
\hline & $R(16)$ & 114962.465 \\
\hline & $R(17)$ & 121498.817 \\
\hline & $R(18)$ & 127994.410 \\
\hline \multirow[t]{6}{*}{$K=1(f)-1(f) ; j_{\mathrm{CO}}=1-1$} & $R(1)$ & $14158^{b}$ \\
\hline & $R(10)$ & $77350.861^{\mathrm{a}}$ \\
\hline & $R(11)$ & $84270.421^{\mathrm{a}}$ \\
\hline & $R(12)$ & $91159.894^{\mathrm{a}}$ \\
\hline & $R(16)$ & 118358.501 \\
\hline & $R(17)$ & 125052.750 \\
\hline \multirow[t]{5}{*}{$K=2(e)-1(e) ; j_{\mathrm{CO}}=2-1$} & $P(8)$ & 138521.998 \\
\hline & $P(9)$ & 132617.887 \\
\hline & $P(10)$ & 126854.034 \\
\hline & $P(11)$ & 121236.214 \\
\hline & $P(12)$ & 115770.536 \\
\hline \multirow[t]{5}{*}{$K=2(f)-1(f) ; j_{\mathrm{CO}}=2-1$} & $P(6)$ & 146163.057 \\
\hline & $P(7)$ & 138473.112 \\
\hline & $P(8)$ & 130695.433 \\
\hline & $P(9)$ & 122835.080 \\
\hline & $P(10)$ & 114897.369 \\
\hline
\end{tabular}

${ }^{\text {a Measured in Ref. } 4 .}$

${ }^{\mathrm{b}}$ Hyperfine-free center frequencies of transitions measured in Ref. 3.

our experimental uncertainty of $50 \mathrm{kHz}$. Including higher order centrifugal parameters $\left(L, \beta_{J}\right)$ improves the fit to some extent but also leads to a high correlation of the rotational parameters.

The authors of the previous MMW study ${ }^{4}$ observed three "mystery" transitions not belonging to already presented series. These transitions exhibited some degree of doubling and were tentatively assigned to the $Q(9), Q(10)$, and $Q(12)$ lines of the $K=2-1$ subbands of para- $\mathrm{NH}_{3}-\mathrm{CO}$. We cannot confirm the proposed assignments because an inclusion of any of these transitions in our analysis significantly worsens the quality of the fit.
TABLE II. Measured $R$-branch transitions for the para- $\mathrm{NH}_{3}-\mathrm{CO}$ complex containing $\mathrm{NH}_{3}$ in the $\left(j_{k}\right)_{\mathrm{NH} 3}=1_{1}$ state. New values are given in bold and represent the $e-e / f-f$ components of the corresponding transition.

\begin{tabular}{|c|c|c|c|}
\hline Assignment & & Frequency, $\mathrm{MHz}$ & Splitting, $\mathrm{MHz}$ \\
\hline \multirow[t]{8}{*}{$K=2-1 ; j_{\mathrm{CO}}=1-0$} & $R(1)$ & $82858.148^{a}$ & $\ldots$ \\
\hline & $R(2)$ & $90102.250^{\mathrm{a}}$ & $\ldots$ \\
\hline & $R(3)$ & $97494.452^{\mathrm{a}}$ & $0.66^{\mathrm{a}}$ \\
\hline & $R(4)$ & $105056.346^{\mathrm{a}}$ & $0.81^{\mathrm{a}}$ \\
\hline & $R(5)$ & $112807.997 / 112807.154$ & 0.84 \\
\hline & $R(6)$ & $120762.295 / 120761.459$ & 0.84 \\
\hline & $R(7)$ & $128925.490 / 128924.650$ & 0.84 \\
\hline & $R(8)$ & $137294.692 / 137293.678$ & 1.01 \\
\hline \multirow[t]{5}{*}{$K=1-1 ; j_{\mathrm{CO}}=0-0$} & $R(1)$ & $13780.4^{\mathrm{b}}$ & $\ldots$ \\
\hline & $R(2)$ & $20665.9^{c}$ & $3.6^{\mathrm{c}}$ \\
\hline & $R(10)$ & $75377.166^{\mathrm{a}}$ & $1.988^{\mathrm{a}}$ \\
\hline & $R(11)$ & $82132.650^{\mathrm{a}}$ & $2.119^{\mathrm{a}}$ \\
\hline & $R(12)$ & $88860.434^{\mathrm{a}}$ & $2.245^{\mathrm{a}}$ \\
\hline \multirow[t]{3}{*}{$K=0-0 ; j_{\mathrm{CO}}=1-1$} & $R(0)$ & $6955.566^{\mathrm{b}}$ & $\ldots$ \\
\hline & $R(1)$ & $13899.339^{\mathrm{b}}$ & $0.086^{\mathrm{b}}$ \\
\hline & $R(2)$ & $20820.4^{b}$ & $\cdots$ \\
\hline \multirow[t]{5}{*}{$K=0-1 ; j \mathrm{CO}=1-0$} & $R(7)$ & $111864.185 / 111787.790$ & 76.395 \\
\hline & $R(8)$ & $118506.310 / 118432.746$ & 73.564 \\
\hline & $R(9)$ & $125027.440 / 124956.454$ & 70.986 \\
\hline & $R(10)$ & $131427.718 / 131359.295$ & 68.423 \\
\hline & $R(11)$ & $137710.853 / 137644.626$ & 66.227 \\
\hline
\end{tabular}

${ }^{a}$ Measured in Ref. 4; the center frequency and observed splitting were reported.

${ }^{\mathrm{b}}$ Hyperfine-free center frequencies of transitions measured in Ref. 3.

${ }^{c}$ From Ref. 3 was not used in fit analysis because of unclear hfs/splitting structure.

\section{CALCULATION OF THE POTENTIAL ENERGY SURFACE}

\section{A. Computational details}

In this part of the work, we used the body-fixed (BF) coordinate system presented in Fig. 3. The origin of coordinate system 1 coincides with the center of mass of the $\mathrm{NH}_{3}$ molecule and the $z$-axis is its threefold symmetry axis. The hydrogen atom labeled $\mathrm{H}^{\prime}$ of the $\mathrm{NH}_{3}$ molecule lies in the $x z$-plane. The intermolecular vector $\boldsymbol{R}$ connects the centers of mass of

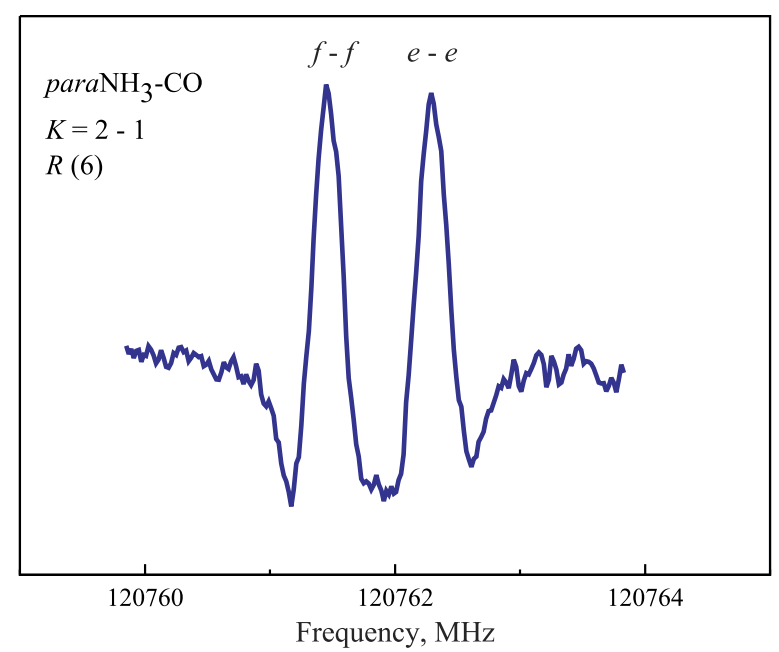

FIG. 2. Recording of the $K=2-1 R(6)$ transition of para- $\mathrm{NH}_{3}-\mathrm{CO}$. Two peaks are due to small $e / f$ symmetry splitting of the energy levels. 
TABLE III. Molecular parameters for the ortho $-\mathrm{NH}_{3}-\mathrm{CO}$ complex composed of $\mathrm{NH}_{3}$ in the $\left(j_{k}\right)_{\mathrm{NH} 3}=0_{0}$ state (all values in $\mathrm{cm}^{-1}$ ).

\begin{tabular}{|c|c|c|c|}
\hline & & Present & Previous work (Ref. 4) \\
\hline \multirow[t]{4}{*}{$K=0$} & $\sigma$ & 0.0 & 0.0 \\
\hline & $B$ & $0.11627260(22)$ & $0.1162725(3)$ \\
\hline & $D$ & $0.36830(16) \times 10^{-5}$ & $0.36790(31) \times 10^{-5}$ \\
\hline & $H$ & $-0.0272(44) \times 10^{-9}$ & $-0.056(11) \times 10^{-9}$ \\
\hline \multirow[t]{8}{*}{$K=1$} & $\sigma$ & $2.2425308(17)$ & $2.242534(3)$ \\
\hline & $B$ & $0.11626456(22)$ & $0.1162657(7)$ \\
\hline & $D$ & $0.30526(16) \times 10^{-5}$ & $0.3055(6) \times 10^{-5}$ \\
\hline & $H$ & $-0.1820(60) \times 10^{-9}$ & $-0.207(16) \times 10^{-9}$ \\
\hline & $L$ & $-0.0908(80) \times 10^{-12}$ & \\
\hline & $b$ & $0.003634257(84)$ & $0.0036374(10)$ \\
\hline & $d$ & $-0.049268(59) \times 10^{-5}$ & $-0.0519(31) \times 10^{-5}$ \\
\hline & $h$ & $-0.702(11) \times 10^{-10}$ & \\
\hline \multirow[t]{5}{*}{$K=2$} & $\sigma$ & $8.9364692(84)$ & {$[8.930]^{\mathrm{a}}$} \\
\hline & $B$ & $0.11619493(41)$ & $0.116238(19)$ \\
\hline & $D$ & $0.24454(52) \times 10^{-5}$ & {$\left[0.261 \times 10^{-5}\right]^{\mathrm{a}}$} \\
\hline & $H$ & $-0.498(22) \times 10^{-9}$ & \\
\hline & $d$ & $-0.063183(83) \times 10^{-5}$ & \\
\hline
\end{tabular}

${ }^{\mathrm{a}}$ Estimated parameter.

the $\mathrm{NH}_{3}$ and $\mathrm{CO}$ molecules. The angles $\theta_{1}$ and $\varphi_{1}$ define the orientation of the vector $\boldsymbol{R}$ in body-fixed frame 1. The rotation of the $\mathrm{CO}$ molecule relative to frame 2 , which is parallel to body-fixed frame 1 , is defined by angles $\theta_{2}$ and $\varphi_{2}$. Thus, the relative orientation of the $\mathrm{NH}_{3}$ and $\mathrm{CO}$ molecules is described by a set of four angles $\left(\theta_{1}, \varphi_{1}, \theta_{2}, \varphi_{2}\right)$.

$A b$ initio calculations were performed for rigid interacting molecules with geometrical structures corresponding to the ground vibrational state: $r_{\mathrm{NH}}=1.916 a_{0}, \angle(\mathrm{HNH})$ $=106.47^{\circ},{ }^{16}$ and $r_{C O}=2.137 a_{0} \cdot{ }^{17}$ It was previously shown for other systems ${ }^{18}$ that the use of the ground vibrational state geometry of the monomers for generation of the intermolecular potential gives a better agreement of theoretical predictions with experiment than the use of the equilibrium geometry.

TABLE IV. Molecular parameters for the para- $\mathrm{NH}_{3}-\mathrm{CO}$ complex composed of $\mathrm{NH}_{3}$ in the $\left(j_{k}\right)_{\mathrm{NH} 3}=1_{1}$ state (all values in $\mathrm{cm}^{-1}$ ).

\begin{tabular}{llll}
\hline \hline & & \multicolumn{1}{c}{ Present } & Previous work (Ref. 4) \\
\hline$K=1$ & $\sigma$ & 0.0 & 0.0 \\
& $B$ & $0.1149299(33)$ & $0.1149333(19)$ \\
& $D$ & $0.2479(24) \times 10^{-5}$ & $0.2503(14) \times 10^{-5}$ \\
& $H$ & $-1.116(55) \times 10^{-9}$ & $-1.060(33) \times 10^{-9}$ \\
$K=0$ & $\sigma$ & $1.757532(89)$ & $1.7591(1)$ \\
& $B$ & $0.1160120(12)$ & $0.116005(5)$ \\
& $D$ & $0.3231(160) \times 10^{-5}$ & $0.03(26) \times 10^{-5}$ \\
& $H$ & $-6.986(140) \times 10^{-9}$ & \\
& & & \\
& & & \\
& & & \\
& & & \\
& & & \\
& $B$ & $0.6450312(55)$ & $0.645011(20)$ \\
& $D$ & $0.4385(190) \times 10^{-5}$ & $0.72(25) \times 10^{-5}$ \\
& $H$ & $-6.22(18) \times 10^{-9}$ & $0.33(25) \times 10^{-8}$ \\
& $\beta$ & $0.0023541(180)$ & $0.00257(21)$ \\
\hline \hline
\end{tabular}

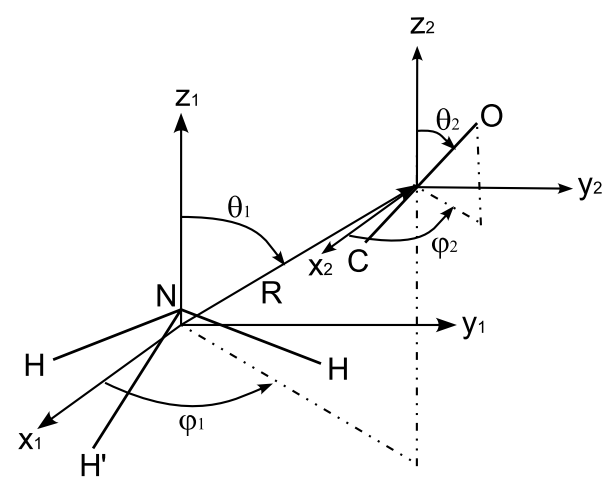

FIG. 3. Coordinate system of the $\mathrm{NH}_{3}-\mathrm{CO}$ system.

It is well known that for the description of noncovalent interactions between molecules that can be described by a single electronic configuration, the golden standard is the $\operatorname{CCSD}(\mathrm{T})$ level in combination with a Complete Basis Set (CBS) limit. Thus, our purpose is to obtain the interaction potential of $\mathrm{NH}_{3}-\mathrm{CO}$ close to this level. First, we have performed some tests to find the most suitable method and basis set (computationally feasible and accurate). The performance of different basis sets, including results extrapolated to the CBS limit (extrapolation scheme of Peterson et al. ${ }^{19}$ ), at the $\operatorname{CCSD}(\mathrm{T})$ level is illustrated in Fig. 4. We also show the results obtained at the explicitly correlated $\operatorname{CCSD}(\mathrm{T})-\mathrm{F} 12 \mathrm{a}^{20}$ and a medium-sized basis set. It was previously shown ${ }^{21-23}$ that the CCSD(T)-F12 method can provide accurate spectroscopic data for bimolecular complexes. It is seen in Fig. 4 that the results close to the reference CCSD(T)/CBS method are obtained by the CCSD(T)-F12a method with an aVTZ basis. ${ }^{24}$ Hence, we calculated the PES of the $\mathrm{NH}_{3}-\mathrm{CO}$ complex in its ground electronic state at the CCSD(T)-F12a level of theory with the aVTZ basis using the MOLPRO 2010 package. ${ }^{25}$ The exponent $\beta$ in the correlation factor $F_{12}$ was set to 1.3 . We used the standard auxiliary basis sets and density fitting functions ${ }^{26,27}$ (CABS(OptRI) basis sets). The basis set superposition error (BSSE) correction was taken into account with the Boys and Bernardi counterpoise scheme ${ }^{28}$ and the interaction potential is given by

$$
\begin{aligned}
V\left(R, \theta_{1}, \varphi_{1}, \theta_{2}, \varphi_{2}\right)= & E_{\mathrm{NH} 3-\mathrm{CO}}\left(R, \theta_{1}, \varphi_{1}, \theta_{2}, \varphi_{2}\right) \\
& -E_{\mathrm{NH} 3}\left(R, \theta_{1}, \varphi_{1}, \theta_{2}, \varphi_{2}\right) \\
& -E_{\mathrm{CO}}\left(R, \theta_{1}, \varphi_{1}, \theta_{2}, \varphi_{2}\right),
\end{aligned}
$$

where the energies of the $\mathrm{NH}_{3}$ and $\mathrm{CO}$ monomers are calculated in the full basis of the complex.

The F12 triple energy correction in MOLPRO is not taken into account directly, but with a scaling term, ${ }^{20}$ which leads to a slight size inconsistency. This size inconsistency was corrected for by subtracting from $V\left(R, \theta_{1}, \varphi_{1}, \theta_{2}, \varphi_{2}\right)$ the asymptotic interaction energy at $R=1000 a_{0}$, which is $6.57 \mathrm{~cm}^{-1}$ for all relative orientations.

The PES calculations were carried out for a large random grid of angular orientations, i.e., for each value of the intermolecular separations $R$, the energies of about 3000 random relative orientations were calculated. The $R$-values were varied from 4.5 to $30 a_{0}$ with 31 radial grid points for each angular orientation. The advantage of using random angular grids is 

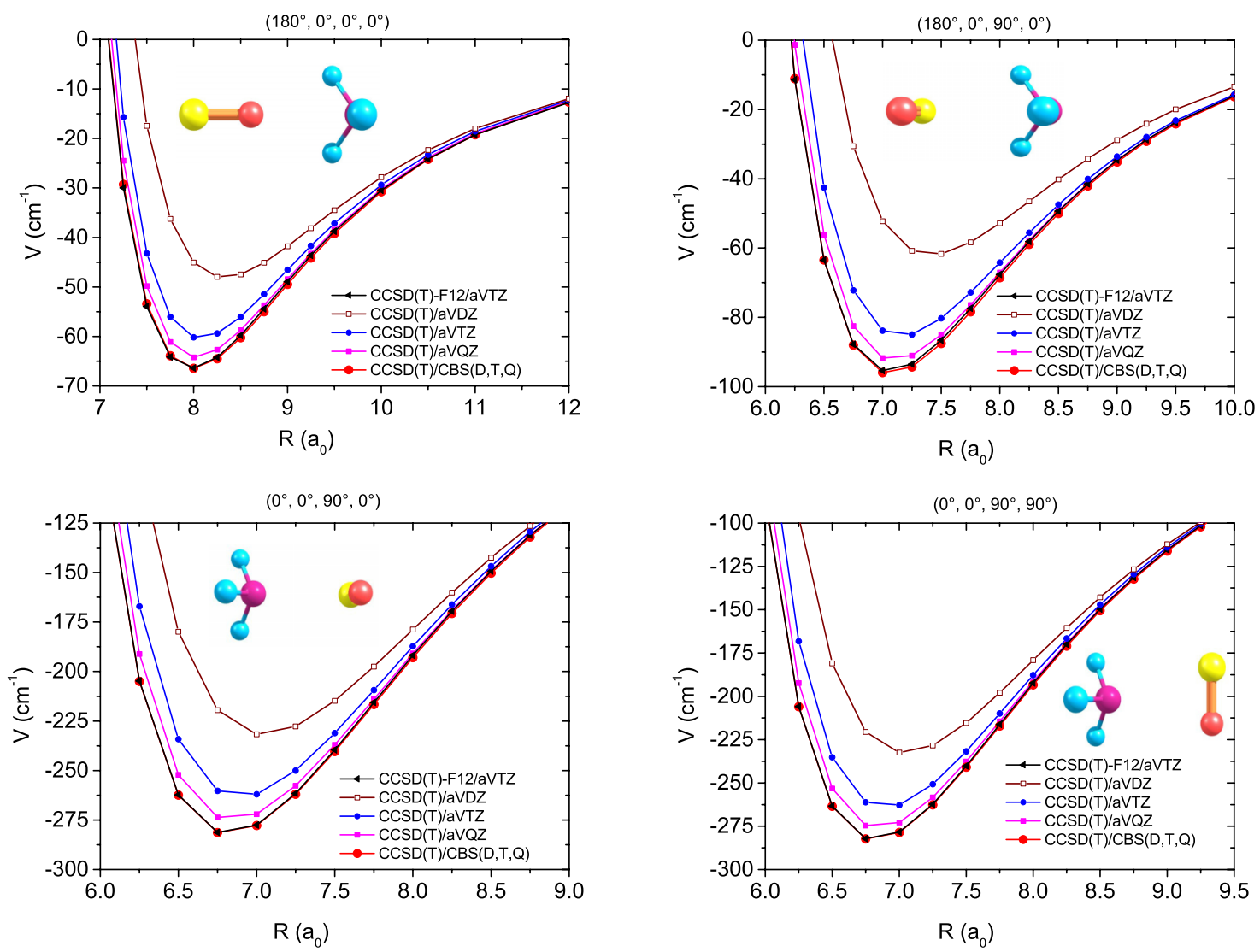

FIG. 4. $\mathrm{NH}_{3}-\mathrm{CO}$ interaction energies for different basis sets and methods as a function of the intermolecular distance for selected angular orientations.

that they allow an estimate of the accuracy of each expansion coefficients, ${ }^{29}$ as illustrated below.

\section{B. Analytical fit}

The analytical expansion for a symmetric-top-linear molecule system can be written as

$$
V\left(R, \theta_{1}, \varphi_{1}, \theta_{2}, \varphi_{2}\right)=\sum v_{l_{1} m_{1} l_{2} l}(R) t_{l_{1} m_{1} l_{2} l}\left(\theta_{1}, \varphi_{1}, \theta_{2}, \varphi_{2}\right),
$$

where the five body-fixed coordinates $\left(R, \theta_{1}, \varphi_{1}, \theta_{2}, \varphi_{2}\right)$ are defined in Fig. 3 and where the functions $t_{l_{1} m_{1} l_{2} l}\left(\theta_{1}, \varphi_{1}, \theta_{2}\right.$, $\left.\varphi_{2}\right)$ are explicitly given by Phillips et al. ${ }^{30}$ and by Valiron et al. ${ }^{31}$ The indices $l_{1}, l_{2}$, and $l$ refer to the tensor rank of the dependence of the potential on the $\mathrm{NH}_{3}$ orientation, the $\mathrm{CO}$ orientation, and the collision vector orientation, respectively. As detailed in Phillips et al. ${ }^{30}$ a phased sum over $\pm m_{1}$ guarantees that the functions are symmetric on reflection in the $\mathrm{NH}_{3}$ molecule $x z$-plane. In the rigid rotor approximation, the $C_{3 V}$ symmetry of $\mathrm{NH}_{3}$ further requires that $m_{1}$ is a multiple of 3 . We selected the maximum tensor ranks in order to include all anisotropies up to $l_{1}=10, l_{2}=10$, and $l=20$, resulting in 2111 expansion functions. We then selected iteratively all significant terms, at each intermolecular separation $R$, using the following procedure: we started the fit with a minimal selection limited to the single function $t_{0000}$ and evaluated the 2110 remaining terms by random quadrature. All terms above a Monte Carlo error estimator (defined by Rist and Faure ${ }^{29}$ ) were then selected and added to $t_{0000}$, providing a new starting expansion. The process was iterated until convergence.
The final set, obtained by merging the selected sets at all distances $R$, was composed of 250 expansion functions, including anisotropies up to $l_{1}=10$ (with $m_{1}=0,3,6$ ), $l_{2}=10$, and $l=18$. The root mean square residual was found to be lower than $1 \mathrm{~cm}^{-1}$ in the long-range and van der Waals well region of the interaction $(R>6 \mathrm{bohr})$. In this part of the PES, the mean error in the expansion coefficients $v_{l_{1} m_{1} l_{2} l}(R)$ was also found to be smaller than $1 \mathrm{~cm}^{-1}$. A cubic spline interpolation of each coefficient $v_{l_{1} m_{1} l_{2} l}(R)$ was finally employed over the whole intermolecular distance range $(R=4.5-30 \mathrm{bohr})$ and it was smoothly connected to standard extrapolations (exponential and inverse power laws at short and long range, respectively) in order to provide continuous radial expansion coefficients suitable for the bound states calculations presented below. Details on the switch function are given by Valiron et al. ${ }^{31}$ see their Eq. (10).

The global minimum of the five-dimensional (5D) PES corresponds to the structure with $\theta_{1}=38.1^{\circ}, \varphi_{1}=0^{\circ}, \theta_{2}$ $=23.2^{\circ}, \varphi_{2}=180^{\circ}$, and $R=6.85 a_{0}$ with binding energy $D_{e}$ $=359.21 \mathrm{~cm}^{-1}$.

In Fig. 5, we present the 2D cuts (other variables are fixed at their equilibrium values corresponding to the global minimum) of the 5D PES of the $\mathrm{NH}_{3}-\mathrm{CO}$ complex. It is noticeable that the potential depends strongly on the orientations of both monomers.

\section{BOUND STATES CALCULATION}

The method used to calculate the rovibrational levels of $\mathrm{NH}_{3}-\mathrm{CO}$ is described in Ref. 32, where it was applied to 

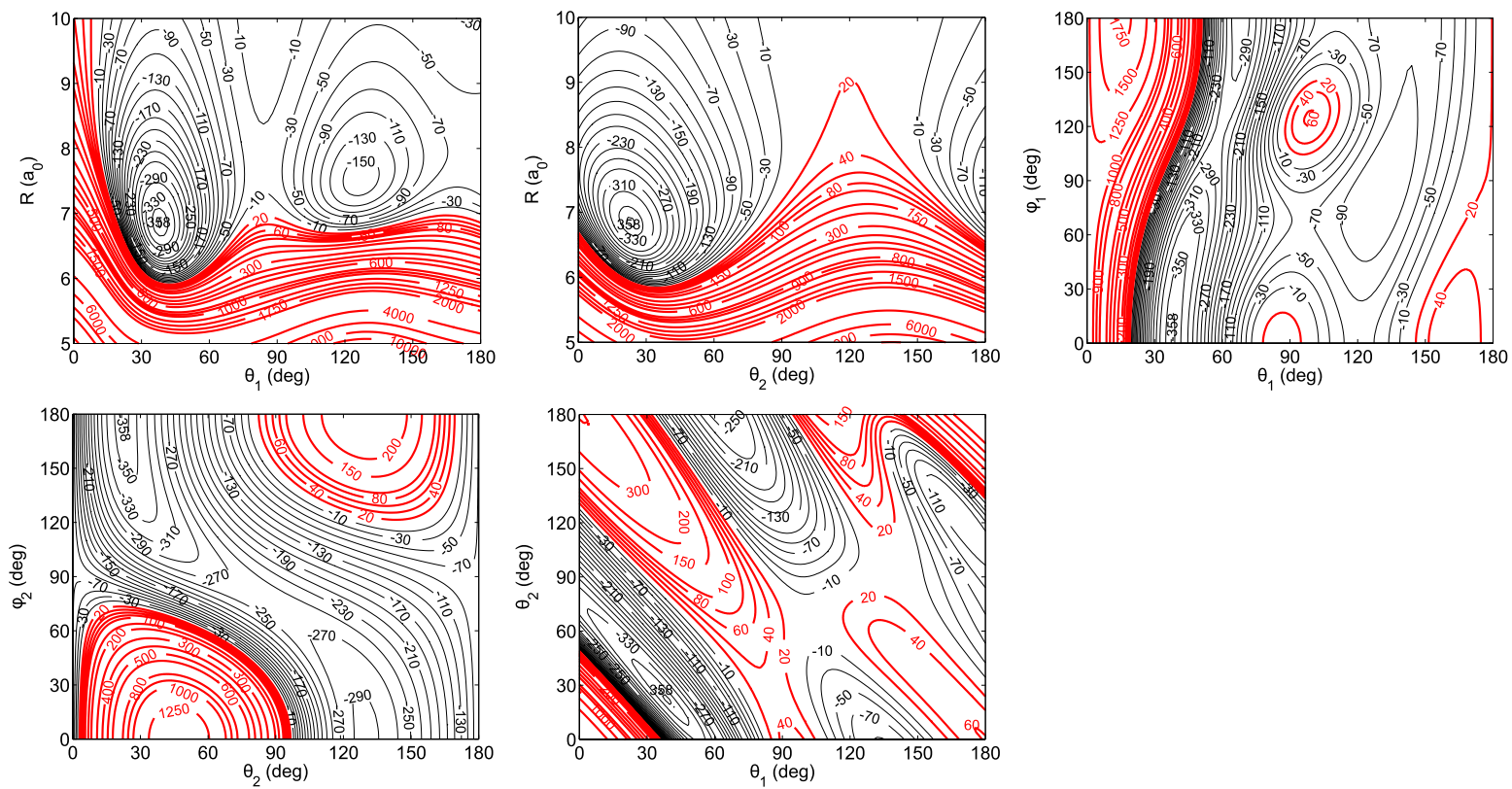

FIG. 5. Potential energy cuts of the 5D PES: two coordinates are changing while others are fixed at their equilibrium values corresponding to the global minimum. Energy contour labels are in $\mathrm{cm}^{-1}$.

$\mathrm{H}_{2} \mathrm{O}-\mathrm{H}_{2}$. It is based on a general computational method ${ }^{33}$ developed for weakly bound molecular dimers with large amplitude internal motions and is similar to a coupled-channel scattering approach. For all details on the form of the Hamiltonian and the basis in BF coordinates, etc., we refer to Ref. 34. $\mathrm{NH}_{3}$ is an oblate symmetric rotor; we used the ground state experimental values for its rotational constants: $A_{0}=B_{0}$ $=9.9402 \mathrm{~cm}^{-1}, C_{0}=6.3044 \mathrm{~cm}^{-1}$, and the measured value of $B_{0}=1.92253 \mathrm{~cm}^{-1}$ for $\mathrm{CO}$. The atomic masses are $1.007825 \mathrm{u}$ for $\mathrm{H}, 14.003074 \mathrm{u}$ for ${ }^{14} \mathrm{~N}, 12$ for ${ }^{12} \mathrm{C}$, and $15.994915 \mathrm{u}$ for ${ }^{16} \mathrm{O}$. The grid in the discrete variable representation (DVR) for the intermolecular center-of-mass distance $R$ contained 162 equidistant points ranging from $R=4.5$ to $20 a_{0}$. We used a radial basis of 20 functions contracted in the same way as in Ref. 32. The angular basis of symmetric rotor functionsWigner $D$-functions ${ }^{34}$ - and spherical harmonics for the hindered rotations of $\mathrm{NH}_{3}$ and $\mathrm{CO}$, respectively, was truncated to internal rotor quantum numbers $j_{\mathrm{NH} 3} \leq 8$ and $j_{\mathrm{CO}} \leq 14$. These values are sufficient to converge the bound levels of the complex to better than $0.01 \mathrm{~cm}^{-1}$, but the energy differences between the levels are converged much more accurately. Also, the overall rotation of the dimer was described with Wigner $D$-functions.

An additional motion in the $\mathrm{NH}_{3}-\mathrm{CO}$ complex is the umbrella inversion tunneling of the $\mathrm{NH}_{3}$ monomer, with a level splitting of $0.7934 \mathrm{~cm}^{-1}$ in the free monomer. As discussed in Sec. V, this tunneling motion is nearly quenched in the dimer states and the corresponding splittings become very small. The potential described in Sec. III does not include this umbrella inversion motion, so we applied a two-state model, which was also used and tested in previous work on $\mathrm{NH}_{3}-\mathrm{He}^{35,36}$ and $\mathrm{NH}_{3}-\mathrm{Ar}^{37}$ This model assumes that the $\mathrm{NH}_{3}$ inversion tunneling motion occurs between two structures, umbrella up and umbrella down, with the umbrella angle corresponding to the equilibrium value in free $\mathrm{NH}_{3}$. The potential was only calculated for one of these structures; its value for the umbrella- inverted structure is obtained from a symmetry relation obeyed by the expansion coefficients described in Sec. III. The twostate model implies that the basis for the rovibrational states of the complex is extended with two $\mathrm{NH}_{3}$ inversion tunneling states that are the plus and minus combinations of the two localized umbrella states. When the $\mathrm{NH}_{3}$ tunneling in the complex is quenched by the interaction with $\mathrm{CO}$, these states become more or less localized.

The permutation-inversion (PI) or molecular symmetry $^{38}$ group $G_{12} \equiv D_{3 h}(M)$ of $\mathrm{NH}_{3}-\mathrm{CO}$ is the same as for $\mathrm{NH}_{3}-\mathrm{He}^{35,36}$ and $\mathrm{NH}_{3}-\mathrm{Ar}^{37}$ The irreducible representations (irreps) of this symmetry group are $A_{1}{ }^{\prime}, A_{1}{ }^{\prime \prime}, A_{2}{ }^{\prime}, A_{2}{ }^{\prime \prime}$, and $E^{\prime}, E^{\prime \prime}$, with states belonging to these irreps having nuclear spin statistical weights ${ }^{38}$ of $0,0,12,12$, and 6,6 , respectively. Since the nuclear spin functions do not change during the measurements, these symmetries are conserved, and the Pauliforbidden states of $A_{1}$ symmetry cannot be observed. The rovibrational wave functions of the $A_{1}$ and $A_{2}$ (ortho) states are composed of $\mathrm{NH}_{3}$ monomer functions with $k_{\mathrm{NH} 3}=0$ (modulo 3 ), while those of $E$-symmetry (para) states have $k_{\mathrm{NH} 3}= \pm 1$ (modulo 3 ). The quantum number $k_{\mathrm{NH} 3}$ is the projection of the $\mathrm{NH}_{3}$ monomer angular momentum $j_{\mathrm{NH} 3}$ on its threefold symmetry axis. Each rovibrational state of $\mathrm{NH}_{3}-\mathrm{CO}$ has two $\mathrm{NH}_{3}$ inversion tunneling components, with $A_{1}{ }^{\prime}$ and $A_{2}{ }^{\prime \prime}$ symmetries, $A_{1}{ }^{\prime \prime}$ and $A_{2}{ }^{\prime}$ symmetries, or $E^{\prime}$ and $E^{\prime \prime}$ symmetries. Since the states of $A_{1}$ symmetry have nuclear spin weight 0 , the inversion tunneling splittings cannot be observed for the ortho states of $\mathrm{NH}_{3}-\mathrm{CO}$. They are visible only in the spectra for the para states of $E$ symmetry.

The total angular momentum $J$ and the parity $p= \pm 1$ under inversion are exact quantum numbers. In our analysis of the rovibrational states, we use the spectroscopic parity $\varepsilon$, which is related to the inversion parity by $p=\varepsilon(-1)^{J}$. We follow the convention to label states of even/odd spectroscopic parity by $e / f$. An approximate quantum number that is important to understand the nature of the rovibrational states 
is the projection $K$ of the total angular momentum $J$ on the intermolecular axis $\boldsymbol{R}$. We use the absolute value of $K$ as a label and distinguish the states with $K>0$ by their parity $e / f$. Calculations have been performed for $J$ values from 0 to 6 for all symmetries.

We found that the ground level of ortho $-\mathrm{NH}_{3}-\mathrm{CO}$ corresponds to $K=0, J=0$ with an energy of $-209.63 \mathrm{~cm}^{-1}$ relative to the separated ortho- $\mathrm{NH}_{3}\left(j_{k}=0_{0+}\right)$ and $\mathrm{CO}(j=0)$ monomers. The even $(+)$ inversion tunneling component of the $j_{k}=0_{0}$ ground state of ortho- $\mathrm{NH}_{3}$ is Pauli-forbidden, however, and since the odd (-) component is $0.79 \mathrm{~cm}^{-1}$ higher in energy, the dissociation energy of ortho- $\mathrm{NH}_{3}-\mathrm{CO}$ is $D_{0}=210.43 \mathrm{~cm}^{-1}$. The ground level of para- $\mathrm{NH}_{3}-\mathrm{CO}$ has $K=1, J=1$ and was calculated at $-202.32 \mathrm{~cm}^{-1}$. Since the ground $\left(j_{k}=1_{1+}\right)$ state of free para- $\mathrm{NH}_{3}$ has an energy of $16.33 \mathrm{~cm}^{-1}$, the dissociation energy $D_{0}$ of para- $\mathrm{NH}_{3}-\mathrm{CO}$ is $218.66 \mathrm{~cm}^{-1}$. Thus, $D_{0}$ is slightly larger for para- $\mathrm{NH}_{3}-\mathrm{CO}$ than for ortho- $\mathrm{NH}_{3}-\mathrm{CO}$. We note, furthermore, that a significant fraction of the binding energy $D_{e}=359.21 \mathrm{~cm}^{-1}$ goes into the zero-point energy associated with the intermolecular vibrations and internal rotations.

\section{DISCUSSION}

The calculated positions of the lower states $\left(<10 \mathrm{~cm}^{-1}\right)$ with $K=0,1,2,3$ of the $\mathrm{NH}_{3}-\mathrm{CO}$ complex that links the subbands detected or searched for in the present work are shown in Fig. 6. The zeros of energies for ortho- $\mathrm{NH}_{3}-\mathrm{CO}$ and para- $\mathrm{NH}_{3}-\mathrm{CO}$ are fixed at their lowest levels. At first sight, one may think that the levels in this picture correspond to a free internal rotor quantum number $j_{\mathrm{CO}}$ increasing from 0 to 1 to 2 and that the observed subbands correlate with $\Delta j_{\mathrm{CO}}=1$. Such a free internal rotor interpretation is not valid, however, since analysis of the calculated wave functions shows that the $j_{\text {CO }}$ values are strongly mixed by the anisotropic interaction potential. According to the bound state calculations, the zero of the para- $\mathrm{NH}_{3}-\mathrm{CO}$ energy scale is about $7 \mathrm{~cm}^{-1}$ higher than the zero of the ortho- $\mathrm{NH}_{3}-\mathrm{CO}$ scale. This number is about half of the value estimated in Ref. 4 assuming free rotation of the $\mathrm{NH}_{3}$ unit in the complex.

It was established in the previous experimental study ${ }^{4}$ and confirmed here by the ab initio calculations that ortho$\mathrm{NH}_{3}-\mathrm{CO}$ has a ground state with $K=0$, while the ground state of para- $\mathrm{NH}_{3}-\mathrm{CO}$ is a $K=1$ state (see Fig. 6). This is related to the fact that the para- $\mathrm{NH}_{3}-\mathrm{CO}$ states begin with $j_{\mathrm{NH} 3}=k_{\mathrm{NH} 3}=1$ and that the lowest energy orientation of para- $\mathrm{NH}_{3}$ in the complex has a $\Pi$ configuration $(K=1)$ with the resultant angular momentum of $\mathrm{NH}_{3}$ oriented parallel to the intermolecular axis of the complex. By contrast, the ortho $-\mathrm{NH}_{3}-\mathrm{CO}$ states begin with $j_{\mathrm{NH} 3}=k_{\mathrm{NH} 3}=0$, and a $\Sigma$ configuration $(K=0)$ has the lowest energy.

Another difference between the two nuclear spin species, as can be seen from Fig. 6, is that the $e / f$ splitting of the $K$ $=1$ and $K=2$ states is much larger for ortho- $\mathrm{NH}_{3}-\mathrm{CO}$ than for para- $\mathrm{NH}_{3}-\mathrm{CO}$. In the theory, this $e / f$ splitting originates from the Coriolis coupling with $\Delta K= \pm 1$ between the $K=0$ levels and the levels with $K>0$, for $K=1$ directly, for $K=2$ indirectly through $K=1$, etc. This explains also why the $e / f$ splittings decrease rapidly with increasing $K$. For ortho$\mathrm{NH}_{3}-\mathrm{CO}$, this mixing occurs only for the $e$ state, not for the $f$ state, because the $K=0$ level has parity $e$. This causes the splitting, because the energy of the $K=1$ level of parity $e$ is changed by the mixing, while the energy of the level of parity $f$ does not change. For para- $\mathrm{NH}_{3}-\mathrm{CO}$, the $K=0$ level occurs with both parities $e$ and $f$. And the $K=1$ levels of $e$ and $f$ parity mix by almost the same amount to the corresponding $K=0$ levels. Hence, there is only a very small splitting between the $e$ and $f$ levels. The reason why for para- $\mathrm{NH}_{3}-\mathrm{CO}$
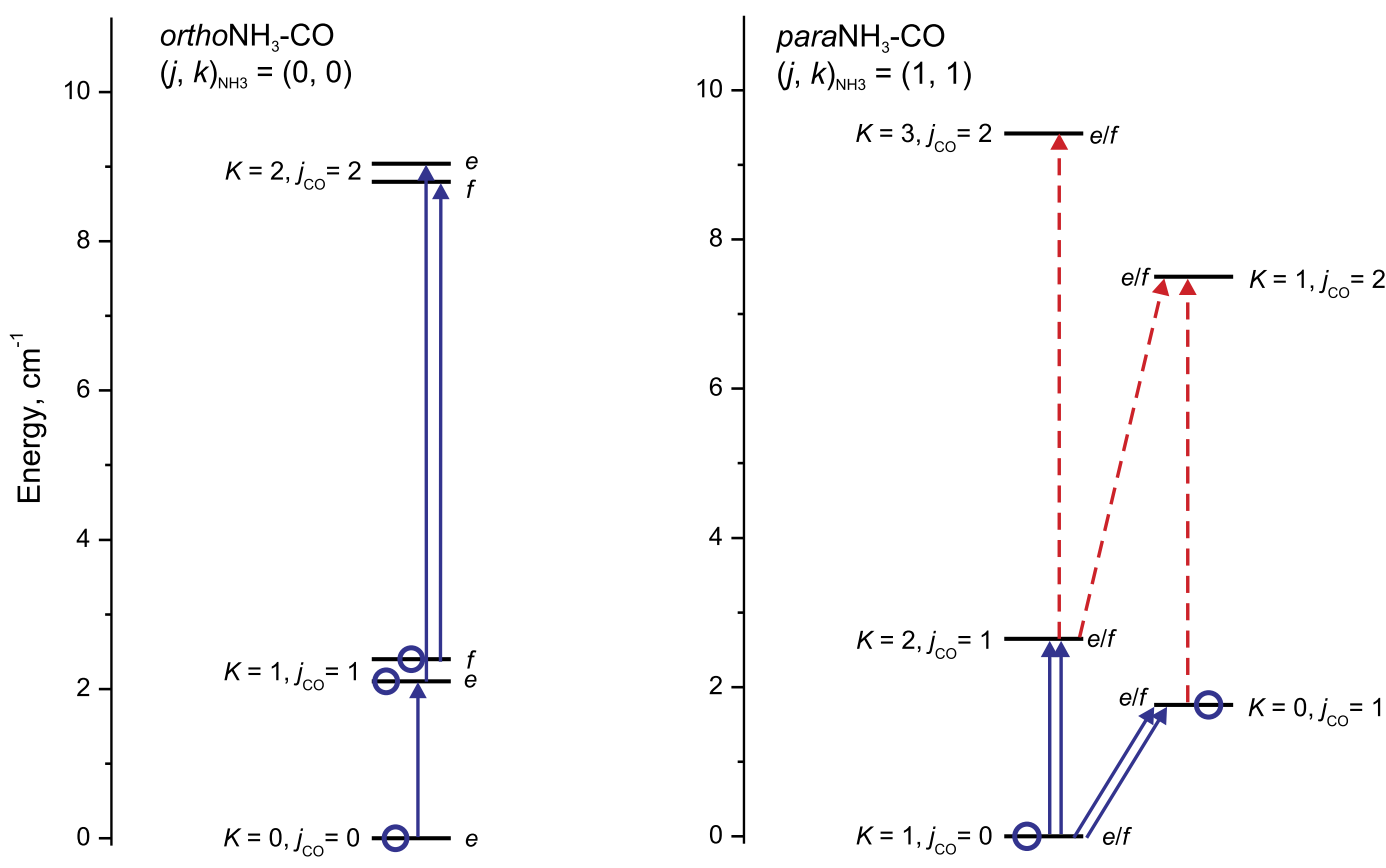

FIG. 6. Calculated energies of the levels with $K=0,1,2,3$ that link the subbands detected (blue solid lines) or searched for (red dashed lines) in the present work. Individual transitions in these subbands are shown in Fig. 1. Circles mean that end-over-end rotational transitions were observed within these states. 
( $E$ symmetry) both parities $e$ and $f$ occur for $K=0$ is because $k_{\mathrm{NH} 3}=1$ for para- $\mathrm{NH}_{3}$. Inversion, which distinguishes $e / f$ (actually $+/-$ ) states, produces two low-lying states, with $k_{\mathrm{NH} 3}=+1$ and -1 . Their plus and minus combinations are the $+/-($ or $e / f)$ states. While for ortho $-\mathrm{NH}_{3}-\mathrm{CO}$, the lowest state has $k_{\mathrm{NH} 3}=0$, so that for $K=0$, only the $e$ state occurs.

The inversion tunneling motion of ammonia is nearly quenched for all states in para- $\mathrm{NH}_{3}-\mathrm{CO}$. Although the calculated splitting of the $K=0$ levels is about 100 times larger than the splitting of the $K=1$ levels, its absolute value of $\sim 80 \mathrm{MHz}\left(\sim 0.003 \mathrm{~cm}^{-1}\right)$ is significantly lower than the inversion splitting in free $\mathrm{NH}_{3}\left(23.9 \mathrm{GHz}\right.$ or $\left.0.79 \mathrm{~cm}^{-1}\right)$. Qualitatively, this picture is the same as observed and calculated for the $\mathrm{NH}_{3}-\mathrm{Ar}$ complex, ${ }^{37,39}$ where the inversion motion of ammonia is hardly affected in the $K=0$ states, while it is nearly quenched in the $K=1$ states. The reason that the inversion splittings are much smaller in $\mathrm{NH}_{3}-\mathrm{CO}$ than in $\mathrm{NH}_{3}-\mathrm{Ar}$ is that the anisotropy of the intermolecular potential is much larger when $\mathrm{NH}_{3}$ interacts with $\mathrm{CO}$ than when it interacts with Ar.

For both spin modifications, all three lowest stacks with $K=0,1,2$ shown in Fig. 6 are now well characterized by MW and MMW spectroscopies. In Table V and Table VI, the experimentally determined energy levels of ortho- $\mathrm{NH}_{3}-\mathrm{CO}$

TABLE V. Calculated ( $a b$ initio) and experimental energy levels of the ortho- $\mathrm{NH}_{3}-\mathrm{CO}$ complex.

\begin{tabular}{|c|c|c|c|c|}
\hline State & $J$ & Calculation, $\mathrm{cm}^{-1}$ & Observation, $\mathrm{cm}^{-1}$ & $\mathrm{O}-\mathrm{C}, \mathrm{cm}^{-1}$ \\
\hline \multirow[t]{7}{*}{$K=0(e)$} & 0 & 0.00000 & 0.00000 & 0.000 \\
\hline & 1 & 0.22729 & 0.23253 & 0.005 \\
\hline & 2 & 0.68179 & 0.69750 & 0.016 \\
\hline & 3 & 1.36333 & 1.39474 & 0.031 \\
\hline & 4 & 2.27167 & 2.32398 & 0.052 \\
\hline & 5 & 3.40647 & 3.48486 & 0.078 \\
\hline & 6 & 4.76732 & 4.87695 & 0.110 \\
\hline \multirow[t]{6}{*}{$K=1(e)$} & 1 & 2.36154 & 2.35516 & -0.006 \\
\hline & 2 & 2.80905 & 2.81288 & 0.004 \\
\hline & 3 & 3.48016 & 3.49930 & 0.019 \\
\hline & 4 & 4.37467 & 4.41421 & 0.040 \\
\hline & 5 & 5.49235 & 5.55734 & 0.065 \\
\hline & 6 & 6.83286 & 6.92835 & 0.095 \\
\hline \multirow[t]{6}{*}{$K=1(f)$} & 1 & 2.36853 & 2.36243 & -0.006 \\
\hline & 2 & 2.83001 & 2.83467 & 0.005 \\
\hline & 3 & 3.52204 & 3.54284 & 0.021 \\
\hline & 4 & 4.44440 & 4.48670 & 0.042 \\
\hline & 5 & 5.59680 & 5.66592 & 0.069 \\
\hline & 6 & 6.97885 & 7.08012 & 0.101 \\
\hline \multirow[t]{5}{*}{$K=2(e)$} & 2 & 9.19981 & 9.16886 & -0.031 \\
\hline & 3 & 9.88105 & 9.86592 & -0.015 \\
\hline & 4 & 10.78915 & 10.79509 & 0.006 \\
\hline & 5 & 11.92396 & 11.95616 & 0.032 \\
\hline & 6 & 13.28526 & 13.34888 & 0.064 \\
\hline \multirow[t]{5}{*}{$K=2(f)$} & 2 & 9.16886 & 9.16884 & -0.031 \\
\hline & 3 & 9.86592 & 9.86583 & -0.015 \\
\hline & 4 & 10.79509 & 10.79483 & 0.006 \\
\hline & 5 & 11.95616 & 11.95559 & 0.032 \\
\hline & 6 & 13.34888 & 13.34776 & 0.063 \\
\hline
\end{tabular}

TABLE VI. Calculated ( $a b$ initio) and experimental energy levels of the para $-\mathrm{NH}_{3}-\mathrm{CO}$ complex (averaged values are given for the $e / f$ components).

\begin{tabular}{llccr}
\hline \hline State & $J$ & Calculation, $\mathrm{cm}^{-1}$ & Observation, $\mathrm{cm}^{-1}$ & O-C, $\mathrm{cm}^{-1}$ \\
\hline$K=1$ & 1 & 0.11241 & 0.11493 & 0.003 \\
& 2 & 0.56202 & 0.57459 & 0.013 \\
& 3 & 1.23629 & 1.26393 & 0.028 \\
& 4 & 2.13503 & 2.18277 & 0.048 \\
& 5 & 3.25802 & 3.33086 & 0.073 \\
& 6 & 4.60495 & 4.70789 & 0.103 \\
$=0$ & 0 & 1.76003 & 1.75895 & -0.001 \\
& 1 & 1.98668 & 1.99096 & 0.004 \\
& 2 & 2.43965 & 2.45460 & 0.015 \\
& 3 & 3.11826 & 3.14909 & 0.031 \\
& 4 & 4.02161 & 4.07340 & 0.052 \\
& 5 & 5.14858 & 5.22626 & 0.078 \\
& 6 & 6.49800 & 6.60636 & 0.108 \\
& 2 & 2.88651 & 2.87877 & -0.008 \\
& 3 & 3.57176 & 3.58008 & 0.008 \\
& 4 & 4.48616 & 4.51600 & 0.030 \\
& 5 & 5.63017 & 5.68707 & 0.057 \\
& 6 & 7.00419 & 7.09371 & 0.090 \\
\hline \hline
\end{tabular}

and para- $\mathrm{NH}_{3}-\mathrm{CO}$ are compared with the results of bound state calculations. The theory predicts very accurately the origins of the observed $K$-stacks as can be seen from comparison of their lowest- $J$ levels, but the (ObservationCalculation) deviations grow rapidly with increasing total angular momentum and amount to about $+0.1 \mathrm{~cm}^{-1}$ at the maximum calculated value of $J=6$. This indicates that the end-over-end rotational constant $[(B+C) / 2]$ from the calculations is too small by about $2 \%$, which corresponds to the average distance $R$ being too large by about $1 \%$. The reason could be that the minimum in the intermolecular potential occurs slightly too far outwards. Calculations with larger basis sets did not produce a shift of the minimum, however. A possible reason for the observed difference may be that our calculations use the rigid monomer model, which may be somewhat inaccurate especially for $\mathrm{NH}_{3}$. The $e / f$ splitting for ortho- $\mathrm{NH}_{3}-\mathrm{CO}$ levels is reproduced by theory with an accuracy better than $0.006 \mathrm{~cm}^{-1}$ for the $K=1$ state and better than $0.0001 \mathrm{~cm}^{-1}$ for the $K=2$ state. The $e / f$ splitting for para- $\mathrm{NH}_{3}-\mathrm{CO}$ levels cannot be determined directly from the experiment, because no transitions between $e$ and $f$ levels were detected. However, the observed splittings for the para$\mathrm{NH}_{3}-\mathrm{CO}$ transitions given in Table II are also very well reproduced by theory, with deviations less than $10 \mathrm{MHz}$ $\left(0.0003 \mathrm{~cm}^{-1}\right)$ for the $K=0-1$ subband and less than $1 \mathrm{MHz}$ $\left(0.00003 \mathrm{~cm}^{-1}\right)$ for the $K=2-1$ subband.

Unfortunately, we were unable to detect the expected subbands for transitions to the $K=3$ state and the second $K=1$ (upper) state (shown by dashed lines in red in Fig. 6). The corresponding $P$-branch transitions were predicted by theory to be in the range of our spectrometer starting from $J=5$ for the $K=1-2, J=7$ for the $K=1-0$, and $J=8$ for the $K=3-2$ subbands. Similar $K=3$ and $K=1$ (upper) stacks of para- $\mathrm{NH}_{3}-\mathrm{CO}$ were observed in the IR work ${ }^{4}$ for the excited $v_{\mathrm{CO}}=1$ state. The authors also estimated the rotational constants (but not directly from experiment) for $K=3$ 
in the ground $v_{\mathrm{CO}}=0$ state. Using these constants, ${ }^{4}$ the expected frequencies for the $K=3-2$ transitions deviate by more than $10 \mathrm{GHz}$, i.e., $0.3 \mathrm{~cm}^{-1}$, from the theoretically predicted values. It makes the search range of the $K=3-2$ subband very uncertain. As mentioned above, the inaccuracy of the theoretical values can be relatively large for such higher $J$ values.

\section{CONCLUSIONS}

This paper describes the new observation of the millimeter-wave spectrum of the $\mathrm{NH}_{3}-\mathrm{CO}$ complex and calculation of the rovibrational bound states on a 5D intermolecular potential surface obtained through high-level $a b$ initio calculations. The observed transitions were assigned to the $K$ $=0-0, K=1-1, K=1-0$, and $K=2-1$ subbands correlating with the rotationless $\left(j_{k}\right)_{\mathrm{NH} 3}=0_{0}$ state $(A$ symmetry) of free ortho- $\mathrm{NH}_{3}$, and the $K=0-1$ and $K=2-1$ subbands correlating with the $\left(j_{k}\right)_{\mathrm{NH} 3}=1_{1}$ state $(E$ symmetry) of free para- $\mathrm{NH}_{3}$. These measurements were included in a simultaneous fit together with the previous data to determine an improved set of empirical molecular parameters for both ortho- $\mathrm{NH}_{3}-\mathrm{CO}$ and para- $\mathrm{NH}_{3}-\mathrm{CO}$. All bound rovibrational levels of the two nuclear spin species were computed for total angular momentum $J=0-6$.

It was found from the calculations that the global minimum of the 5D PES corresponds to a structure with intermolecular separation $R=6.85 a_{0}$ and binding energy $D_{e}=359.21 \mathrm{~cm}^{-1}$. The $C_{3}$ axis of the $\mathrm{NH}_{3}$ subunit is oriented at an angle of $38.1^{\circ}$ with respect to the axis connecting the centers of mass of the two subunits and the $\mathrm{N}$ atom is closest to the $\mathrm{CO}$ subunit. A significant fraction of the binding energy goes into the zero-point energy associated with the intermolecular vibrations and internal rotations: the dissociation energies $D_{0}$ are 210.43 and $218.66 \mathrm{~cm}^{-1}$ for ortho- $\mathrm{NH}_{3}-\mathrm{CO}$ and para- $\mathrm{NH}_{3}-\mathrm{CO}$, respectively.

The computed energy levels were compared with the rotational spectra measured earlier and in the present work. We found a good agreement with the experiment for all detected stacks although we noted a systematic increase of the rotational energy differences with increasing $J$, which indicates that the calculated end-over-end rotational constant of the complex is too small by about $2 \%$. The reason for the latter deviation may be the use of a rigid monomer model, especially for $\mathrm{NH}_{3}$.

Finally, we can conclude that the present results provide a considerable amount of new information, both experimental and theoretical, which elucidate the intermolecular interactions and dynamics in the $\mathrm{NH}_{3}-\mathrm{CO}$ system.

\section{ACKNOWLEDGMENTS}

This work was supported by Deutsche Forschungsgemeinschaft (DFG) through research Grant No. SU 579/12 and by Russian Foundation for Basic Research through Grant No. 15-03-09333. A.P. acknowledges support by DFG via SFB 956. Y.K. acknowledges the support of Russian Foundation for Basic Research (Project No. 13-05-00751).
Ab initio calculations were carried out using HPC resources of Skif-Cyberia (Tomsk State University).

${ }^{1}$ Solar System Ices, edited by B. Schmitt, C. De Bergh, and M. Festou (Kluwer, Dordrecht, 1998).

${ }^{2}$ L. J. Allamandola, M. P. Bernstein, S. A. Sandford, and R. L. Walker, Space Sci. Rev. 90, 219 (1999).

${ }^{3}$ G. T. Fraser, D. D. Nelson, Jr., K. I. Peterson, and W. Klemperer, J. Chem. Phys. 84, 2472 (1986).

${ }^{4}$ C. Xia, K. A. Walker, and A. R. W. McKellar, Mol. Phys. 99, 643 (2001).

${ }^{5}$ A. R. W. McKellar, J. Chem. Phys. 108, 1811 (1998).

${ }^{6}$ A. V. Potapov, L. A. Surin, V. A. Panfilov, B. S. Dumesh, T. F. Giesen, S. Schlemmer, P. L. Raston, and W. Jäger, Astrophys. J. 703, 2108 (2009),

${ }^{7}$ M. Rezaei, K. H. Michaelian, N. Moazzen-Ahmadi, and A. R. W. McKellar, J. Phys. Chem. A 117, 13752 (2013).

${ }^{8}$ L. Surin, A. Potapov, H. S. P. Müller, and S. Schlemmer, J. Mol. Spectrosc. 307, 54 (2015).

${ }^{9}$ C. Xia, K. A. Walker, and A. R. W. McKellar, J. Chem. Phys. 114, 4824 (2001).

${ }^{10}$ Y. Liu and W. Jäger, J. Chem. Phys. 121, 6240 (2004).

${ }^{11}$ A. V. Potapov, A. A. Dolgov, V. A. Panfilov, L. A. Surin, and S. Schlemmer, J. Mol. Spectrosc. 268, 112 (2011).

${ }^{12}$ W. Gordy and R. L. Cook, Microwave Molecular Spectra, 3rd ed. (John Wiley \& Sons Inc., 1984).

${ }^{13}$ B. S. Dumesh and L. A. Surin, Rev. Sci. Instrum. 67, 3458 (1996).

${ }^{14}$ L. A. Surin, B. S. Dumesh, F. Lewen, D. A. Roth, V. P. Kostromin, F. S. Rusin, G. Winnewisser, and I. Pak, Rev. Sci. Instrum. 72, 2535 (2001).

${ }^{15}$ L. A. Surin, D. N. Furzikov, T. F. Giesen, S. Schlemmer, G. Winnewisser, V. A. Panfilov, B. S. Dumesh, G. W. M. Vissers, and A. van der Avoird, J. Phys. Chem. A 111, 12238 (2007).

${ }^{16} \mathrm{G}$. Herzberg, Infrared and Raman Spectra of Polyatomic Molecules, Molecular Spectra and Molecular Structure Vol. 2 (Van Nostrand, New York, 1945), p. 632.

${ }^{17}$ K. P. Huber and G. Herzberg, Molecular Spectra and Molecular Structure. IV. Constants of Diatomic Molecules (Van Nostrand Reinhold, New York, 1979).

${ }^{18}$ P. Jankowski and K. Szalewicz, J. Chem. Phys. 123, 104301 (2005).

${ }^{19}$ K. A. Peterson, D. E. Woon, and T. H. Dunning, Jr., J. Chem. Phys. 100, 7410 (1994).

${ }^{20}$ H.-J. W. G. Knizia and T. B. Adler, J. Chem. Phys. 130, 054104 (2009).

${ }^{21}$ Y. Ajili, K. Hammami, N. E. Jaidane, M. Lanza, Y. N. Kalugina, F. Lique, and M. Hochlaf, Phys. Chem. Chem. Phys. 15, 10062 (2013).

${ }^{22}$ F. Lique, J. Klos, and M. Hochlaf, Phys. Chem. Chem. Phys. 12, 15672 (2010).

${ }^{23}$ Y. Kalugina, I. Buryak, Y. Ajili, A. Vigasin, N.-E. Jaidane, and M. Hochlaf, J. Chem. Phys. 140, 234310 (2014).

${ }^{24}$ T. H. Dunning, J. Chem. Phys. 90, 1007 (1989).

${ }^{25}$ H.-J. Werner, P. J. Knowles, G. Knizia, F. R. Manby, M. Schütz et al., MOLPRO, version 2010.1, a package of ab initio programs, 2010, see http: //www.molpro.net.

${ }^{26}$ W. Klopper, Mol. Phys. 99, 481 (2001).

${ }^{27}$ F. Weigend, A. Köhn, and C. Hättig, J. Chem. Phys. 116, 3175 (2002).

${ }^{28}$ S. F. Boys and F. Bernardi, Mol. Phys. 19, 553 (1970).

${ }^{29}$ C. Rist and A. Faure, J. Math. Chem. 50, 588 (2011).

${ }^{30}$ T. R. Phillips, S. Maluendes, A. D. McLean, and S. Green, J. Chem. Phys. 101, 5824 (1994).

${ }^{31}$ P. Valiron, M. Wernli, A. Faure, L. Wiesenfeld, C. Rist, S. Kedžuch, and J. Noga, J. Chem. Phys. 129, 134306 (2008).

${ }^{32}$ A. van der Avoird and D. J. Nesbitt, J. Chem. Phys. 134, 044314 (2011).

${ }^{33}$ G. C. Groenenboom, P. E. S. Wormer, A. van der Avoird, E. M. Mas, R. Bukowski, and K. Szalewicz, J. Chem. Phys. 113, 6702 (2000).

${ }^{34}$ D. M. Brink and G. R. Satchler, Angular Momentum, 3rd ed. (Clarendon, Oxford, 1993).

${ }^{35}$ K. B. Gubbels, S. Y. T. van de Meerakker, G. C. Groenenboom, G. Meijer, and A. van der Avoird, J. Chem. Phys. 136, 074301 (2012).

${ }^{36}$ O. Tkac, A. Kumar Saha, J. Onvlee, C.-H. Yang, G. Sarma, C. Bishwarkarma, S. Y. T. van de Meerakker, A. van der Avoird, D. H. Parker, and A. J. Orr-Ewing, Phys. Chem. Chem. Phys. 16, 477 (2014).

${ }^{37}$ J. Loreau, J. Liévin, Y. Scribano, and A. van der Avoird, J. Chem. Phys. 141, 224303 (2014).

${ }^{38}$ P. R. Bunker and P. Jensen, Molecular Symmetry and Spectroscopy, 2nd ed. (NRC Research Press, Ottawa, Canada, 1998).

${ }^{39}$ E. Zwart, H. Linnartz, W. Leo Meerts, G. T. Fraser, D. D. Nelson, Jr., and W. Klemperer, J. Chem. Phys. 95, 793 (1991). 